\title{
Una crítica político-antropológica al «choque de civilizaciones» de Samuel P. Huntington
}

\author{
ANNA QUINTANAS \\ Universidad de Girona
}

Después de la caída del muro de Berlín en noviembre de 1989 han surgido diversos paradigmas que intentan dar cuenta de la nueva situación mundial. Los dos paradigmas que han conseguido un éxito más rotundo han sido los ofrecidos por F. Fukuyama y S. P. Huntington. En este artículo vamos a centrarnos en la crítica de las tesis de Huntington, pero al mostrar el contexto que da sentido y enmarca sus ideas, nos aparecerá la proximidad existente entre ambos autores. Aparentemente las tesis de Huntington sobre el «choque de civilizaciones» implican una crítica y una descalificación de la apuesta de Fukuyama por el «final de la historia». Sin embargo, si se contextualizan sus teorías, lo que sale a la luz es algo muy distinto. Lo más importante, a pesar de las diferencias existentes entre las interpretaciones de estos dos autores, es lo que tienen en común. Fukuyama y Huntington intentan naturalizar, justificar y aplaudir el sistema neoliberal que domina actualmente nuestro mundo globalizado. Son dos perfectos representantes del intelectual del establishment, son como dos caras de la misma moneda.

Para comprender cuáles son los intereses que motivaron y generaron las tesis del «final de la historia» y del «choque de civilizaciones» es necesario hacer referencia al proceso que posibilitó el éxito creciente de las tesis neoliberales y neoconservadoras, proceso íntimamente ligado a los «think tanks» norteamericanos y a las fundaciones benéficas que financian estos laboratorios de ideas ${ }^{1}$.

Después de la Segunda Guerra Mundial, las tesis neoliberales eran defendidas por sectores muy minoritarios. En los EUA y la Europa Occidental se estaba viviendo una época de crecimiento económico que, junto a la presión ejercida por el miedo al éxito de las ideas comunistas, facilitó que los Estados occidentales dedicaran una parte importante de sus recursos a construir unos servicios públicos destinados a paliar las desigualdades sociales y económicas existentes. Así se edificaron las bases del Estado del bienestar, una política que combinaba la empresa privada con la existencia de un Estado fuerte encargado de proteger los sectores más desfavorecidos de la sociedad y garantizar a todos sus ciudadanos derechos básicos como la educación y la sanidad. A partir de la larga recesión provocada por la crisis energética de los años setenta, las tesis neoliberales empezaron a abrirse camino culpando de la situación a la excesiva injerencia de los Estados y las administraciones públicas en los asuntos sociales y económicos. En los años ochenta, las políticas de $\mathrm{M}$. Thatcher y R. Reagan dieron un impulso decisivo a las tesis neoliberales, aplicando medidas a favor de la «retirada» del Estado y confiando en el poder de autorregulación de los mercados: reducción del gasto público, disminución de los impuestos, privatizaciones, desregulación de la economía, etc. Pero fue a partir de los noventa, con el desmembramiento de la antigua URSS, cuando las tesis neoliberales pasaron de ser defendidas por sectores minoritarios a convertirse en la ideología dominante.

Fue en este contexto que apareció en escena F. Fukuyama. Tras el desplome del «socialismo real», Fukuyama sostuvo que 
aparecería un consenso generalizado en torno a la democracia liberal occidental. Hegelianamente, presentó a la democracia liberal como el punto final de la evolución ideológica de la humanidad. Lo único relevante que nos depararía el futuro sería la exportación, a escala mundial, de la democracia formal basada en el sistema económico neoliberal. Pero después de la Guerra del Golfo y del conflicto de la ex-Yugoslavia, las tesis de Fukuyama sobre un mundo felizmente neoliberal cayeron en desgracia. $Y$ fue Huntington el encargado de ofrecer una nueva visión conservadora de la situación internacional a partir de su paradigma sobre el «choque de civilizaciones».

Fukuyama y Huntington representan dos puntos estelares dentro de la maniobra orquestada por la ideología neoliberal para difundir su ideario e introducirlo en las prácticas políticas de los gobiernos. Dentro de esta calculada estrategia, los «think tanks» y las fundaciones benéficas norteamericanas han jugado un papel principal. Los laboratorios de ideas de tendencia neoliberal son centros de investigación que analizan y elaboran propuestas de actuación sobre los diversos ámbitos de la vida política, económica y social de los EUA, teniendo como principal objetivo la influencia de su ideario en la política interior y exterior de este país. Algunos de estos laboratorios de ideas tienen un pronunciado carácter académico, como es el caso de la Rand Corporation, donde trabaja Fukuyama, o del American Enterprise Institute, donde colabora Jeane Kirkpatrick. Otros laboratorios centran sus actuaciones más abiertamente en el activismo político, como es el caso de la Heritage Foundation o la Progress and Freedom Foundation. También hay laboratorios que, como el Cato Institute, combinan ambas estrategias.

Estos laboratorios de ideas neoliberales y neoconservadoras son financiados por fundaciones benéficas de carácter privado que están relacionadas con los más impor- tantes grupos industriales y financieros de los EUA. El gran capital y sus intereses son los que crean, desarrollan y popularizan las tesis de autores como Fukuyama y Huntington. Por poner sólo algunos ejemplos, la Heritage Foundation y el American Enterprise Institute son subvencionados por la Bradley Foundation, y el Cato Institute es financiado por la David H. Koch Charitable Foundation. Los recursos económicos de estas dos fundaciones benéficas provienen de algunas de las empresas petroleras más importantes de los EUA. Además, la Heritage Foundation recibe fondos de la Sarah Scaife Foundation (banca), y el American Enterprise Institute se beneficia también de los fondos aportados por la Eli Lilly Foundation (productos farmacéuticos).

$\mathrm{Si}$ los grandes grupos industriales $\mathrm{y}$ financieros, a través de fundaciones benéficas, favorecen los laboratorios de ideas neoliberales es porque desde estas instituciones se intenta influir sobre el gobierno estadounidense para que aplique medidas que protejan y garanticen sus intereses. A autores como Fukuyama y Huntington les corresponde entonces la tarea de ofrecer a los políticos argumentos técnicos para defender y legitimar la necesidad de estas medidas e intentar camuflar, de esta forma, cuáles son los intereses que están realmente en juego.

El poder de estas fundaciones privadas no se debe subestimar, ya que no sólo se dedican a financiar laboratorios de ideas, sino que también extienden su influencia hasta el mundo universitario, el mundo editorial y el de los medios de comunicación de masas. Su capital se utiliza para fines muy diversos, como la subvención de revistas y libros, la promoción de determinado tipo de debates o la creación de plazas de profesores, cátedras y centros de investigación dentro del ámbito universitario. Dos de las fundaciones privadas más relevantes de los EUA son la E. A. Morris Foundation (tabacalera) y la John $M$. Olin 
Foundation. El capital de la John M. Olin Foundation surgió originariamente de una importante empresa de municiones y armas ligeras que, posteriormente, debido a una fusión, se convirtió en la Olin-Mathieson Chemical Company, una de las principales empresas químicas norteamericanas.

La Fundación Olin nos interesa especialmente porque sus recursos económicos fueron los principales responsables de la difusión mundial de las tesis de Fukuyama y Huntington. Las ramificaciones de esta fundación privada son extensas. Su capital se destina a un amplio abanico de actividades. Entre sus principales beneficiarios figuran algunas de las universidades más prestigiosas de los EUA, como Harvard, Chicago, Yale y Stanford; algunas de las revistas que juegan un papel más importante en la defensa del sistema, como The National Interest o Foreign Affairs, donde aparecieron, respectivamente, los artículos de Fukuyama y Huntington ${ }^{2}$; algunos de los más activos laboratorios de ideas neoliberales, como The Progress and Freedom Foundation, American Enterprise Institute, Heritage Foundation y Cato Institute. También cabe destacar, teniendo en cuenta las claras relaciones establecidas entre el gran capital y las empresas armamentísticas, sus aportaciones en la investigación de temas de estrategia militar y seguridad nacional. La Fundación Olin subvenciona programas de investigación y enseñanza sobre temas militares en la Academia de la Fuerza Aérea de Colorado o en la Academia militar de West Point, en el Center for Strategic and International Studies o en el United States Global Strategy Council. Y evidentemente también está detrás del Instituto John M. Olin de Estudios Estratégicos de Harvard que, hasta enero del 2000, fue dirigido por Huntington.

La Fundación Olin utilizó una estrategia muy parecida para promocionar las tesis, primero de Fukuyama, y luego de Huntington $^{3}$. En 1988, Allan Bloom, que dirigía el centro Olin de Chicago, invitó a Fukuyama a exponer sus ideas. De esta conferencia surgió, en 1989, su famoso artículo, antes citado, sobre el fin de la historia, que fue publicado en The National Interest, la revista de la fundación. En un número posterior de la revista, para intentar crear la sensación de debate, aparecieron críticas de Allan Bloom, Irving Kristol y Huntington a las tesis de Fukuyama. Entonces se convocó a la prensa y así se allanó el camino para la publicación del libro que habría de convertir a Fukuyama en una figura reconocida a escala mundial, y más allá del ámbito estrictamente académico ${ }^{4}$. Pero, como decíamos antes, los conflictos del Golfo y de la ex-Yugoslavia ensombrecieron la esperanza de Fukuyama sobre la marcha triunfal de la democracia occidental neoliberal sobre el planeta entero. Y entonces Huntington tomó el relevo publicando, en 1993, su artículo sobre el choque de civilizaciones en Foreing Affairs, más tarde aparecieron una serie de réplicas de otros autores y, finalmente, se publicó su famoso libro sobre la misma cuestión ${ }^{5}$.

Después de ilustrar las relevantes implicaciones económico-políticas que envuelven las tesis de Fukuyama y Huntingon, queremos centrarnos en Huntington porque sus interpretaciones del orden internacional han reaparecido con fuerza después de los acontecimientos del 11 de setiembre y su influencia nos parece especialmente perniciosa. Según Huntington, la vieja rivalidad entre las dos superpotencias de la Guerra Fría está siendo substituida por el choque de civilizaciones. Por tanto, los conflictos más importantes no estarán motivados especialmente por causas ideológicas, ni políticas, ni tan sólo económicas, sino sobre todo por causas relacionadas con las diferencias entre civilizaciones. Huntington habla de la existencia de ocho civilizaciones: china, japonesa, islámica, hindú, ortodoxa, latinoamericana, occidental y africana. Aunque consi- 
dera que en la nueva situación mundial los Estados-nación continuarán siendo los actores principales, afirma que sus políticas se dejarán influir no sólo por intereses económicos y de poder, sino sobre todo por las diferencias y coincidencias culturales. La política internacional estará dominada por unas complejas y difíciles relaciones entre grandes agrupaciones culturales, es decir, entre las llamadas «civilizaciones» 6 .

Frente al optimismo de Fukuyama con relación al triunfo gradual pero definitivo de los valores y las instituciones de la democracia liberal occidental, Huntington declaraba que estábamos asistiendo al inicio de la decadencia de la civilización Occidental debido al progresivo aumento de poder por parte de las civilizaciones no occidentales. Según Huntington sería una auténtica irresponsabilidad que Occidente bajara la guardia, pues en este nuevo mundo multicivilizacional corría el riesgo de perder su supremacía. Huntington estima que el control de Occidente sobre la mayoría de recursos importantes habría llegado a su punto culminante a principios del siglo $\mathrm{xx}$, mientras que a partir de entonces su poder habría empezado a declinar. Ante este estado de decadencia, el consejo de Huntington a Occidente es el de rearmarse ante los nuevos enemigos que serían, sobre todo, el mundo islámico y el mundo asiático. China, que bien podría convertirse en una gran rival en el ámbito económico, y el mundo árabe, con su aumento espectacular de la población, serán, según Huntington, las dos fuentes principales de donde emanará el cuestionamiento del liderazgo mundial de Occidente.

Aunque Fukuyama y Huntington parecen situarse en puntos de vista muy distintos, no debemos olvidar que ambos autores toman claramente partido a favor de los intereses de Occidente, dejando al llamado Tercer Mundo en una posición secundaria y dependiente. En el caso de Fukuyama se presupone la victoria final de Occidente a escala mundial. En el caso de Huntington simplemente se avisa de la posibilidad de que otras civilizaciones se atrevan a mantener un pulso con Occidente, pero con sus tesis se encarga de ofrecer consejos para que al final la balanza continúe decantándose del lado de Occidente.

Después del 11 de setiembre, las tesis de Huntington devienen especialmente peligrosas porque se ha insinuado que al menos uno de los nuevos enemigos de la civilización Occidental pronosticados por este autor se habría materializado de la forma más impresionante que alguien hubiera podido imaginar. Efectivamente hay quien ha querido interpretar los acontecimientos del 11 de setiembre como un choque entre la civilización occidental y la civilización islámica, potenciándose de esta manera la desconfianza que ya mucho antes se había ido creando, por diferentes medios, con relación a todo lo que proviniese del mundo islámico, una desconfianza claramente subrayada en las ideas de Huntington.

Huntington compara la importancia de lo que llama el «Resurgimiento islámico» con la Revolución francesa, la Revolución americana o la Revolución rusa ${ }^{7}$. Insiste en la transcendencia de la explosión demográfica acontecida en el mundo árabe combinada con el orgullo renovado que estaria experimentando esta civilización respecto a sus propios valores, instituciones y cultura. Aunque considera que todas las civilizaciones no occidentales en general estarían pasando por un estadio de renacimiento debido a su crecimiento económico, militar y político, cree que el mundo árabe, junto al mundo asiático, $\mathrm{y}$ sobre todo China, representarán la principal amenaza. Con el islam y China, dice Huntington, es probable que Occidente mantenga relaciones tensas y a menudo antagónicas. Mientras que sus relaciones con Latinoamérica y África registrarán grados de tensión mucho más débiles, y las rela- 
ciones con Rusia, Japón y la India se situarán en una posición intermedia.

Las tesis de Huntington están impregnadas de un profundo etnocentrismo que implica un claro prejuicio respecto a las culturas no occidentales y, especialmente, en relación con la civilización islámica, sobre la cual realiza afirmaciones realmente preocupantes: «las fronteras del islam son sangrientas, y también lo son sus áreas $\mathrm{y}$ territorios internos» $\mathrm{y}$ «la belicosidad y violencia musulmanas son hechos de finales del siglo $\mathrm{xx}$ que ni musulmanes ni no musulmanes pueden negar» ${ }^{8}$. Huntington afirma que el mundo musulmán se define por un plus de violencia y belicosidad comparado con las demás civilizaciones. Describe seis causas que explicarían por qué los musulmanes estarían implicados en mucha más violencia intergrupal que los individuos de otras civilizaciones y porque los Estados de la civilización árabe serían mucho más propensos a recurrir a la violencia en las crisis internacionales.

En primer lugar, el islam habría sido, desde sus orígenes, una religión glorificadora de la espada y exaltadora de las virtudes castrenses. En segundo lugar, debido a la expansión del islam, los musulmanes habrian entrado en contacto directo con muchos pueblos diferentes y esta situación generaría una fuente constante de disputas. En tercer lugar, considera que el islam, más que el cristianismo, es «una fe absolutista» porque funde el ámbito religioso y el político, y establece una línea divisoria muy marcada entre los que pertenecen al Dar al-Islam y los que constituyen el Dar al-Harb. Por este motivo piensa que confucianos, budistas, cristianos occidentales y cristianos ortodoxos siempre tendrán menos dificultades para adaptarse unos a otros, que las que cualquiera de ellos pueda tener a la hora de intentar convivir con musulmanes. Estas tres causas (militarismo, proximidad a grupos no musulmanes y indigestabilidad) serían características constantes en el islam y cree que pueden explicar lo que él percibe como una clara propensión musulmana al conflicto a lo largo de la historia. El islam, por naturaleza, tendría tendencias violentas, según Huntington.

Además de estas constantes inherentes al islam, habría tres factores más, en este caso circunstanciales, que podrían contribuir a explicar su propensión a la violencia y al conflicto en la actualidad. Uno de estos factores, al cual, significativamente, no le da demasiada importancia, sería el victimismo y el resentimiento que experimentaría el mundo musulmán debido a los efectos sufridos por el imperialismo occidental. Un segundo factor, mucho más relevante, sería la ausencia de uno o más Estados centrales en la civilización islámica. Los Estados aspirantes a ser líderes dentro del mundo musulmán, como Arabia Saudita, Irán, Paquistán, Turquía y potencialmente Indonesia, rivalizan para ejercer una influencia predominante, pero ninguno de ellos goza de una posición de fuerza suficiente que le permita actuar de intermediario en los conflictos internos del islam o actuar con autoridad, en nombre del mundo islámico, en caso de conflicto entre musulmanes y no musulmanes. Finalmente, el último factor sería la explosión demográfica producida en las sociedades musulmanas y la existencia de un gran contingente de jóvenes varones, de entre quince y treinta años, a menudo en el paro, que constituyen «una fuente natural de inestabilidad y violencia, tanto dentro del islam, como contra no musulmanes ${ }^{9}$. Este factor por sí solo, según Huntington, explicaría buena parte de la violencia musulmana de los años ochenta y noventa. $Y$ considera que el envejecimiento de esta generación, alrededor de la tercera década del siglo XXI, podría comportar una importante reducción de «las propensiones musulmanas a la violencia» ${ }^{10}$.

Como se puede comprobar, los análisis de Huntington sobre la civilización islámica son realmente maniqueos y si en la 
actualidad estos estereotipos son los que se instalan en la mente del gobierno norteamericano, tal como pretende Huntington, las consecuencias pueden ser realmente nefastas y generar conflictos bélicos mucho más graves que la Guerra de Afganistán. Y es que Huntington asegura que, además de esta propensión especial y profunda a la violencia por parte de la civilización islámica, existe un enfrentamiento eterno entre el cristianismo, una de las bases de la civilización occidental, y el islam. Para Huntington el conflicto entre la democracia liberal y el marxismo-leninismo, por ejemplo, tan sólo sería un simple fenómeno histórico, fugaz y pasajero, comparado con la tensión continuada y profundamente intensa entre el islam y el cristianismo. A lo largo de la historia, el cristianismo y el islam siempre se habrían erigido, cada uno de ellos, como el Otro del otro, y afirma que «las causas de esta tónica constante de conflicto no estriban en fenómenos transitorios, como la pasión cristiana del siglo XI o el fundamentalismo musulmán del siglo $\mathrm{xx}$, sino que dimanan de la naturaleza de estas dos religiones y de las civilizaciones basadas en ellas» 11 . Para Huntington el conflicto entre la civilización árabe y la occidental no es circunstancial, sino substancial. Se trata de un conflicto eterno que proviene de la misma naturaleza de cada una de estas civilizaciones que se basan en religiones y valores que siempre entrarán en colisión.

Huntington es muy claro aconsejando a Occidente sobre la actitud que debe tomar respecto a las demás civilizaciones, y sobre todo en relación con China y la civilización islámica. Si Occídente está en crisis mientras las demás civilizaciones van aumentando gradualmente su poder, Occidente no debe abandonar, bajo ningún concepto, la carrera armamentística. Huntington sólo ve a las demás civilizaciones como enemigos potenciales. Su obsesión por la peligrosidad del Otro es recurrente en todos sus escritos. $\mathrm{Y}$ ante este miedo a la diferencia su respuesta se sitúa claramente en torno a la cultura de la guerra. Huntington ha afirmado de forma rotunda que la no proliferación de armamento proclamada por Occidente es un claro error estratégico y está convencido de que este tipo de política está condenada al fracaso. Occidente debe aceptar, como un hecho inevitable, que las demás civilizaciones se dediquen a aumentar su capacidad militar. Occidente tendría que pasar de la oposición a la proliferación de armamento a adaptarse a ella. De lo que se trata, aclara Huntington sin ruborizarse, es que Occidente encuentre la manera de conseguir que el hecho de promover la proliferación de armamento pueda servir a los intereses norteamericanos y occidentales.

Para intentar dar más realismo a sus hipótesis sobre el choque de civilizaciones que se avecina, no muestra reparos en recrear una posible tercera guerra mundial ${ }^{12}$. Huntington se imagina un futuro enfrentamiento bélico entre los EUA y China que acabaría implicando buena parte de la humanidad: un misil con carga nuclear, lanzado desde Argelia, explotaría en las afueras de Marsella; después de superar las proclamas pacifistas que en los EUA protagonizarían los hispanos, que estarían dominando el sudoeste del país, se iniciaría una tercera guerra mundial que enfrentaría dos grandes bloques; los EUA, Europa, Rusia y la India lucharían contra China, Japón y la mayoría del mundo islámico. Este conflicto podría finalizar con la mutua devastación nuclear, con una pausa negociada, o bien con la marcha triunfal de las fuerzas rusas y occidentales hasta la plaza de Tiananmen. Por supuesto, no hace referencia a la posibilidad de que el enemigo consiguiera plantarse victorioso ante la misma ciudad de Nueva York.

Aún así, piensa que, una vez finalizada la contienda, los EUA se verían inmersos en una fuerte crisis que provocaría que amplios sectores de la opinión pública culpasen de la mala situación en que habría 
quedado el país a la estrecha orientación occidental de las elites WASP (blancas, anglosajonas y protestantes) $\mathrm{y}$, una vez más, los líderes hispanos saldrían a escena y conseguirían alcanzar el poder apoyados por la promesa de una amplia ayuda proporcionada por los países latinoamericanos, los cuales habrían quedado al margen de la guerra. Lo poco que quedase de Europa sería devorado por las masas que llegarían de África. En Asia, Indonesia, que habría permanecido neutral, se convertiría en el nuevo Estado dominante. En todo caso, lo más remarcable de la nueva situación mundial sería que el centro del poder global se habría desplazado del norte hacia el sur.

Huntington, aprovechándose de su enorme erudición y su gran conocimiento sobre política internacional, es capaz de construir, en primer lugar, unos enemigos para la civilización Occidental, que serían, potencialmente, todas las demás civilizaciones, las no occidentales, y especialmente el mundo islámico y el mundo asiático. En segundo lugar, muestra su habilidad y su falta de escrúpulos a la hora de afear al enemigo, sobre todo subrayando la gran incompatibilidad existente entre la civilización occidental y la islámica, e inventándose una agresividad extra inherente al mundo musulmán. Si el enemigo es inevitable, y además es tan peligroso que incluso es posible recrear una tercera guerra mundial, Occidente sólo puede reaccionar de una forma si aún tiene sentido común. Debe seguir aumentando sus presupuestos militares, en caso contrario, perderá la capacidad de dominio de la que goza en la actualidad.

Pero Huntington no sólo recurre al consejo militarista, sino que también hace referencia a la necesidad y a la urgencia de defender los valores, las instituciones y el estilo de vida occidentales. Para contrarrestar el aumento de poder de las civilizaciones no occidentales, Occidente debe rearmarse militarmente pero también cul- turalmente. Occidente debe ser más occidental que nunca. Para Huntington la civilización occidental incluye Norte América, Europa, Australia y Nueva Zelanda, aunque en sus escritos prácticamente se olvida de Australia y Nueva Zelanda, y se centra de forma clara en los EUA. A lo largo de la historia, según Huntington, Occidente habría atravesado por una primera fase de dominio europeo y una segunda fase de dominio norteamericano. Huntington apuesta por la posibilidad de una tercera fase, en este caso euroamericana, que sólo será posible si Occidente sabe reaccionar adecuadamente ante los nuevos retos internacionales:

«Occidente atravesó una primera fase europea de desarrollo y expansión que duró varios siglos, y después una segunda fase americana en el siglo xx. Si Norte América y Europa renuevan su vida moral, construyen sobre su coincidencia cultural y desarrollan formas exclusivas de integración económica y política para complementar su colaboración en materia de seguridad en la OTAN, podrían generar una tercera fase euroamericana de prosperidad económica e influencia política occidental. Una integración política significativa contrarrestaría en cierta medida la decadencia relativa en la proporción de Occidente respecto a la población, el producto económico y el potencial militar del mundo, y restablecería el poder de Occidente a los ojos de los líderes de otras civilizaciones. (...) Sin embargo, el que Occidente se una o no políticamente y económicamente depende sobre todo de que los Estados Unidos se reafirmen en su identidad como nación occidental y definan su papel a escala mundial como líder de la civilización occidental» ${ }^{13}$.

Huntington plantea esta cuestión de forma muy taxativa. El futuro no garantiza necesariamente que la civilización occidental continúe liderando el orden internacional. De la actitud que adopte Occidente depende el hecho de si sabrá renovarse y salir de su actual estado de crisis o, por el contrario, continuará su degeneración interna acelerando su final como civiliza- 
ción o inaugurando un nuevo periodo de subordinación a otras civilizaciones económicamente y demográficamente más dinámicas. Para facilitar el advenimiento de una tercera fase euroamericana, es necesario reforzar la colaboración económico-política entre Europa y los EUA, y afianzar de forma rotunda el papel de la OTAN. El recurso militarista es indispensable. Pero para que esta colaboración sea posible, afirma ,Huntington, los EUA deben apresurarse a reafirmar su identidad como nación occidental. Así pues, Huntington también exige como requisito imprescindible para el futuro liderazgo de Occidente que la identidad norteamericana sepa proteger cuidadosamente su pureza occidental. Huntington teme al peligro de que Occidente se esté desoccidentalizando.

A parte de los enemigos externos, la civilización islámica y la confuciana, Huntington hace referencia a dos grupos de población que, desde el interior mismo de Occidente, estarían en posición de cuestionar las mismas esencias de esta civilización. En primer lugar, tendríamos a los inmigrantes de otras civilizaciones que rechazan la integración y siguen adhiriéndose y propagando los valores, costumbres y culturas de sus sociedades de origen. Este fenómeno estaría bien representado por la presencia de un número considerable de musulmanes en Europa, a pesar de continuar siendo una minoría, y en menor grado, por la presencia de los hispanos en los EUA, que conforman una gran minoría.

En segundo lugar, Huntington señala la existencia de un pequeño pero influyente grupo de intelectuales y publicistas compatriotas suyos que representarían uno de los peligros internos más graves e inmediatos para la sociedad norteamericana. Esta plaga interna son los multiculturalistas. Como se puede comprobar, Huntington tiene problemas con la diversidad tanto a escala nacional como en el ámbito inter- nacional. El principal enemigo interno de los EUA lo conforman todos aquellos que cuestionan la verdadera identidad nacional norteamericana, basada culturalmente en la herencia de la civilización occidental y políticamente en la libertad, la democracia, el individualismo, la igualdad ante de la ley, el constitucionalismo y, por supuesto, la defensa de la propiedad privada. En nombre del multiculturalismo, estos amenazadores grupos estarían minando la identificación de los EUA con la civilización occidental y negarían la existencia de una cultura norteamericana común, mientras se dedicarían a promover identidades y agrupaciones raciales, étnicas y culturales de diferente tipo a nivel subnacional. A estos críticos de la perspectiva monocultural defendida por Huntington, se los cataloga de «separatistas etnocéntricos» y son acusados de «buscar inyecciones redentoras de culturas no occidentales» ${ }^{14}$.

Esta tendencia multicultural derivaría, según Huntington, de la perniciosa legislación sobre derechos civiles introducida en los años sesenta. En los años noventa, en la misma línea, Clinton habría convertido el estímulo de la diversidad en uno de sus objetivos primordiales. Para Huntington los multiculturalistas representan una terrible amenaza para la pureza occidental de la identidad norteamericana porque desearían que los EUA se convirtieran en un país de múltiples civilizaciones que foo sólo asumiera el legado occidental. Esta posibilidad resulta aterradora e inviable para el profesor de Harvard:

«La historia demuestra que ningún país asi constituido puede pervivir largo tiempo como una sociedad coherente. Unos Estados Unidos de múltiples civilizaciones no serán los Estados Unidos, serán las Naciones Unidas» ${ }^{15}$.

Consecuentemente con su definición esencialista y excluyente de lo que es una civilización, Huntington afirma que el choque entre los multiculturalistas y los defen- 
sores de la civilización occidental y del verdadero estilo de vida norteamericano constituye el «verdadero choque» ${ }^{16}$. Del hecho que los norteamericanos sepan reafirmar, sin fisuras, su adhesión a la civilización occidental, y se alejen radicalmente de los «diversos y subversivos cantos de sirena del multiculturalismo» ${ }^{17}$, depende no sólo el futuro de los EUA, sino el futuro de la civilización occidental en su conjunto, porque bien poca cosa sería esta civilización sin la presencia de su líder norteamericano:

«El rechazo del credo y de la civilización occidental supone el final de los Estados Unidos de América tal y como los hemos conocido. También significa realmente el final de la civilización occidental. Si los Estados Unidos se desoccidentalizan, Occidente queda reducido a Europa y a unos pocos países ultramarinos de colonos europeos escasamente poblados. Sin los Estados Unidos, Occidente se convierte en una parte minúscula y decreciente de la población del mundo, en una península pequeña y sin trascendencia, situada en el extremo de la masa continental euroasiática» ${ }^{18}$.

Además de la autoafirmación occidental de la identidad nacional de los EUA, también resulta necesario, según Huntington, regenerar los pilares sobre los que se erige la propia civilización occidental, unos pilares que también estarían siendo erosionados por un proceso de «decadencia moral» que se manifestaría básicamente en las siguientes cinco tendencias:

«El aumento de la conducta antisocial, como crímenes, drogadicción y violencia en general. La decadencia familiar, que incluye mayores tasas de divorcio, ilegitimidad, embarazos de adolescentes y familias monoparentales. $\mathrm{Al}$ menos en los Estados Unidos, el descenso del "capital social», esto es, del número de miembros de asociaciones de voluntariado y de la confianza interpersonal asociada con tal colectivo. El debilitamiento general de la «ética del trabajo" y el auge de un culto de tolerancia personal. El interés cada vez menor por el estudio y la actividad intelectual, manifestado en los Estados Unidos en unos niveles inferiores de rendimiento escolars ${ }^{19}$.

Huntington considera que una parte fundamental del futuro de Occidente y de su influencia sobre las demás civilizaciones depende de su habilidad para afrontar con éxito estas tendencias decadentes que resquebrajan la solidez de la cultura occidental y ofrecen motivos a las civilizaciones islámica y asiática para proferir declaraciones de superioridad moral. Los norteamericanos deben jugar un papel protagonista para trabajar por la superación de la actual etapa crítica por la cual está atravesando la civilización occidental, y lo deben hacer, sin duda, reafirmándose en la idea siguiente:

«Culturalmente, los norteamericanos son parte de la familia occidental; los multiculturalistas pueden dañar e incluso destruir esa relación, pero no pueden reemplazarla. Cuando los estadounidenses buscan sus raíces culturales, las encuentran en Europas ${ }^{20}$.

Si Huntington es capaz de realizar este tipo de afirmaciones, entonces resulta comprensible que sólo pueda llegar a pensar el mundo en términos de choque entre civilizaciones. Si no reconoce la diversidad inherente dentro de su propio país, tampoco la respetará en el ámbito internacional. Pero éste no es en absoluto su objetivo. No le interesa pensar un orden mundial más justo donde sea posible construir un equilibrio de poder entre los diferentes países que, a su vez, permita la convivencia armoniosa y enriquecedora entre las diversas culturas. Su obra está destinada exclusivamente a encontrar la manera de proteger y promocionar los intereses y los valores occidentales. Si sus tesis acaban influyendo en la política norteamericana, el futuro que nos aguarda no será precisamente bucólico. Con una postura tan partidista el choque del que habla Huntington tiene muchas posibilidades de llegar a materializarse. Sobre todo si tenemos 
en cuenta que Huntington parte de la idea de que sólo es posible afirmar la propia civilización, no sólo negando la diversidad interna, sino también marcando la oposición respecto a las demás civilizaciones. Huntington es un claro ejemplo de integrismo occidental, de mentalidad estrecha, salpicada de restos camuflados de auténtica xenofobia:

«El demagogo nacionalista veneciano que aparece en la novela de Michael Dibdin, Dead Lagoon, expresaba bien una severa Weltans chauung de esta nueva era: "No puede haber verdaderos amigos sin verdaderos enemigos. A menos que odiemos lo que no somos, no podemos amar lo que somos. Éstas son las viejas verdades que vamos descubriendo de nuevo dolorosamente tras más de un siglo de hipocresía sentimental. iQuienes las niegan, niegan a su familia, su herencia, su cultura, su patrimonio y a sí mismos! No se les perdonará fácilmente". La funesta verdad de estas viejas verdades no puede ser ignorada por hombres de Estado e investigadores» ${ }^{21}$.

Los hombres de Estado y los investigadores deben reconocer como verdad universal que para amar lo que somos, tenemos que odiar lo que no somos. Y que nadie se escandalice, porque, según el profesor de Harvard, la afirmación de lo propio pasa necesariamente por la negación de los otros: «sabemos quiénes somos sólo cuando sabemos quiénes no somos, y con frecuencia sólo cuando sabemos contra quiénes estamos». Aunque Huntington habla de la necesidad de crear unas Naciones Unidas que incluyan como miembros permanentes a países representantes de las diferentes civilizaciones y también hace referencia a la conveniencia de intentar crear una moral mínima extraída de los elementos comunes a las diferentes civilizaciones, estas muestras de buena voluntad, o de hipocresía, no son compatibles con el hecho de aconsejar a Occidente que se repliegue sobre sí mismo y que trate a los «otros» como enemigos. Pero cuando, como en el caso de Huntington, el otro es visto como la negación de uno mismo, no puede ser tolerado bajo ningún concepto, y de forma inevitable se intentará impedir su desarrollo. Huntington muestra tener muy asumida la competitividad que supone que, por definición, para ganar es necesario que el otro pierda. Le parece natural que se odie a los que representan el papel del otro porque, dice, la gente necesita enemigos: competidores en los negocios, rivales en el rendimiento académico $u$ opositores en la política. Y si se resuelve un conflicto y desaparece un enemigo, cree que es inevitable que se generen fuerzas personales, sociales y políticas que den origen a otros nuevos enemigos. No parece que Huntington pueda llegar a imaginar, ni remotamente, que la humanidad también puede ser el reconocimiento de uno mismo en el otro, y con el otro.

Es importante resaltar que detrás de la oposición que Huntington marca entre la civilización occidental y las demás civilizaciones, lo que se encuentra de hecho es la distancia que separa el Primer Mundo del Tercer Mundo. A Huntington le interesa magnificar la importancia de la parte cultural porque pretende dejar de lado las graves diferencias económicas que separan los países ricos de los más empobrecidos. Con su «choque de civilizaciones» creemos que Huntingon lo que pretende es impedir que veamos que los graves problemas de nuestro mundo tienen como principales causas las terribles desigualdades económicas existentes. Pero la construcción de un mundo más justo no entra dentro de los cálculos de Huntington ya que sólo contempla las medidas que Occidente debe tomar para seguir siendo la potencia dominante:

«El cambiante equilibrio de poder entre civilizaciones hace que para Occidente sea cada vez más difícil lograr sus objetivos en cuanto se refiere a la proliferación armamentística, los derechos humanos, la inmigración y otras cues- 
tiones. Para minimizar sus pérdidas en esta situación, Occidente tiene que manejar hábilmente sus recursos económicos, como zanahorias y palos, al tratar con otras sociedades, para alentar su unidad y coordinar sus políticas a fin de dificultar a otras sociedades que enfrenten a una sociedad occidental contra otra, y para ahondar y explotar las diferencias entre las naciones no occidentales» ${ }^{22}$

Dentro de Occidente la unión y la colaboración son imprescindibles, pero el trato para con los «otros», que ya se han definido previamente como enemigos, debe regirse por otros parámetros. Occidente debe ahondar y explotar las diferencias existentes entre los países no occidentales. Que los enemigos se enfrenten entre ellos es una ventaja, sin duda. Y para rematar la cuestión de la alta política internacional, también debe quedar claro que el gran poder económico de Occidente debe ser utilizado como «zanahorias y palos». El cinismo de Huntington es impresionante, pero refleja bastante bien cuál ha sido la política de su país, con la colaboración de Europa, en relación con el Tercer Mundo. Pero entonces, ìpor qué nos sorprendieron tanto los acontecimientos del 11 de setiembre? ¿Qué le queda al Tercer Mundo ante la arrogancia y la prepotencia del mundo occidental? Evidentemente si no aceptamos la cultura de la guerra defendida por Huntington y aplicada por los gobiernos occidentales, tampoco justificamos las respuestas violentas y criminales que puedan venir de otras latitudes. Sólo pretendemos señalar que la situación marginal de la mayor parte de la población mundial, si no se soluciona, seguirá provocando estallidos de violencia. La mejor defensa es trabajar por la justicia. Y el profesor Huntington, con su paradigma financiado por el gran capital industrial y financiero, no contribuye en absoluto a ello. Queremos imaginar cómo deben sentirse los ciuda- danos del Tercer Mundo, y especialmente los del mundo árabe, cuando leen las siguientes valoraciones de Huntington sobre la Guerra del Golfo. En este caso, aunque se empecina en interpretarla como una guerra de civilizaciones, no puede dejar de mostrar cuáles fueron los intereses reales e innegables de esta contienda:

«La guerra del Golfo fue la primera guerra de recursos intercivilizatoria de la posguerra fría. Lo que estaba en juego era si el grueso de las mayores reservas petrolíferas del mundo sería controlado por los gobiernos de Arabia Saudí y de los emiratos, dependientes del poderío militar occidental para su seguridad, o por regímenes antioccidentales independientes, que podrían y estarían dispuestos a usar el arma del petróleo contra Occidente. Occidente no consiguió derrocar a Saddam Hussein, pero se anotó en cierto modo una victoria al poner de manifiesto la dependencia respecto a Occidente de los Estados del Golfo en materia de seguridad y al conseguir una mayor presencia militar en el Golfo en tiempo de paz. Antes de la guerra, Irán, Irak, el Consejo de Cooperación del Golfo y los Estados Unidos pugnaban para asegurar su influencia sobre el Golfo. Tras la guerra, el Golfo Pérsico era un lago estadounidense» ${ }^{23}$

Esta descripción tan pura y dura es bien conocida en el Tercer Mundo, aunque allá no se celebre con gran regocijo. La civilización occidental, en nombre de la libertad, la democracia y los derechos humanos obliga al resto del mundo - con políticas neoliberales que empobrecen y llevan a la miseria a la mayoría de la población, o abiertamente con ataques militares-a ser un «lago», una propiedad disponible y utilizable para el Primer Mundo. Occidente no sólo dispone de sus propios recursos, sino también de la expropiación y el expolio de los recursos del Tercer Mundo. Huntington, con su ampulosa teoría del «choque de civilizaciones», pretendería hacérnoslo olvidar, pero no lo consigue. 


\section{NOTAS}

${ }^{1}$ Sobre esta cuestión cf. Marc Dueñas, «Introducció», en Marc Dueñas (ed.), Xoc de civilitzacions. A l'entorn de S. P. Huntington i el debat sobre el xoc de civilitzacions, Barcelona, Proa, 1997, pp. 11-54.

${ }^{2}$ F. Fukuyama, «The End of History?», The Natio nal Interest, núm. 16, verano 1989. Samuel P. Huntington, «The Clash of Civilizations?», Foreing Affairs, verano 1993.

${ }^{3}$ Sobre esta cuestión cf. Josep Fontana, «Samuel Huntington, el conflicte de civilitzacions i la fàbrica Olin de producció de teoria conservadora», en Marc Dueñas (ed.), Xoc de civilitzacions. A l'entorn de $S$. $P$. Huntington i el debat sobre el xoc de civilitzacions, Barcelona, Proa, 1997, pp. 163-171.

${ }^{4}$ F. Fukuyama, The End of History and the Last Man, Londres, Hamish Hamilton, 1992. También se editó en los EUA en The Free Press. Traducción en castellano El fin de la historia y el último hombre, Barcelona, Planeta, 1992.

${ }^{5}$ Samuel $\mathrm{P}$. Huntington, The Clash of civilizations and the remaking of world order, Nueva York, Simon \& Schuster, 1996. Traducción en castellano El choque de civilizaciones y la reconfiguración del orden mundial, Barcelona, Paidós, 1997.
6 Para Huntington la civilización sería la entidad cultural más amplia que se define por elementos objetivos comunes, como la lengua, la historia, la religión las costumbres, las instituciones, y por la autoidentificación subjetiva de los individuos.

7 Cf. Samuel P. Huntington, El choque de civilizaciones y la reconfiguración del orden mundial, Barcelona, Paidós, 1997, p. 130

${ }^{8}$ Ibid., pp. 308 y 310

${ }^{9}$ Ibid., pp. 317-318.

10 Ibid., p. 318.

11 Ibid., p. 251.

12 Cf. ibid., pp. 375-379.

${ }_{13}$ Ibid, p. 369.

14 Ibid., p. 366.

is Ibid., p. 367.

16 Ibid., p. 368.

17 Ibid., p. 368.

${ }_{18}$ Ibid., pp. 367-368.

${ }_{19}$ Ibid., p. 365

${ }^{20}$ Ibid., p. 368.

${ }_{21}$ Ibid., p. 20.

22 Ibid., pp. 245-246.

${ }^{23}$ Ibid., pp. 301-302. 